\title{
Câncer de língua x trauma crônico e xerostomia: há relação?
}

Tongue cancer $x$ chronic trauma and xerostomia: Is there a relationship?

Cáncer de lengua $x$ trauma crónico y xerostomía: ¿Hay alguna relación?

\section{Yamille de Lima SOUZA ${ }^{1}$ \\ Tiago Novaes PINHEIRO² \\ Lioney Nobre CABRAL ${ }^{3}$}

${ }^{1}$ Curso de Graduação em Odontologia da Universidade do Estado do Amazonas (UEA) 69065-001, Manaus - AM, Brasil

${ }^{2}$ Doutor em Patologia Bucal pela Universidade de São Paulo, USP, Professor Adjunto do Curso de Graduação em Odontologia, Universidade do Estado do Amazonas (UEA) 69065-001, Manaus - AM, Brasil

${ }^{3}$ Doutor em Biotecnologia pela Universidade Federal do Amazonas, UFAM, Professor Adjunto do Curso de Graduação em Odontologia, Universidade do Estado do Amazonas (UEA) 69065-001, Manaus - AM, Brasil

\section{Resumo}

O carcinoma espinocelular (CEC) é a neoplasia maligna mais comum da cavidade oral, sendo seus agentes etiológicos principais: o álcool, tabaco e o Papilomavirus Humano (HPV) de alto risco, porém, existem outras possibilidades etiopatogênicas ainda não amiudadas pela ciência. Este trabalho relata caso de paciente do gênero feminino, 48 anos, não tabagista, não etilista e sem sinal de infecção pelo vírus HPV, com queixa de lesão nodular em ventre lingual. Relatou hábito de "chupar a língua" desde tenra idade, boca seca e ardência bucal há alguns meses e, ao exame físico, apresentou ordenha negativa das glândulas parótidas, baixa coleta nas sublinguais e submandibulares. Apresentava sinais de comprometimento muscular cervical, massetérico e, por conseguinte, bucinatório, condição que pode concorrer fisicamente para estenose do ducto parotídeo e redução da secreção parotídea. Após diagnóstico de CEC, a paciente foi submetida a tratamento cirúrgico, radio e quimioterápico. Para o controle do hábito parafuncional, provavelmente relacionado à lesão que evoluiu para o CEC, foram realizados: uso de dispositivo interoclusal, fisioterapia e crioterapia com prescrição de saliva artificial e creme reparador para as lesões mucosas, decorrentes da hipo/assialia. Consideramos que a associação do trauma crônico, fator modificador clássico, resultante da atividade parafuncional e a redução do fluxo salivar promovida- entre outras razões orgânicas primárias, prévias ao tratamento radio e quimioterápico- pelo potencial estreitamento do ducto de Stenon em razão da disfunção mastigatória, como promotora da perda de homeostasia local e não controle de iniciadores endógenos e/ou exógenos, concorreram para o desenvolvimento da condição neoplásica.

Descritores: Carcinoma de Células Escamosas; Saliva; Pontos-Gatilho; Homeostase.

\section{Abstract}

Squamous cell carcinoma (SCC) is the most common malignant neoplasm of the oral cavity, and its main etiological agents: alcohol, tobacco and high-risk human papillomavirus (HPV), however, there are other etiopathogenic possibilities that have not yet been helped by science. This paper reports a case of a 48-year-old female patient, non-smoker, non-alcoholic and with no sign of HPV virus infection, complaining of nodular lesion in the lingual belly. She reported the habit of "sucking the tongue" from an early age, dry mouth and burning mouth for some months and, on physical examination, she presented negative milking of the parotid glands, low collection in the sublingual and submandibular glands. He showed signs of cervical, masseteric and, consequently, buccinatory muscle involvement, a condition that can physically contribute to parotid duct stenosis and reduced parotid secretion. After diagnosing SCC, the patient underwent surgical, radio and chemotherapy treatment. For the control of parafunctional habit, probably related to the lesion that evolved to SCC, the following were performed: use of interocclusal device, physical therapy and cryotherapy with prescription of artificial saliva and repair cream for mucosal lesions, resulting from hypo/assialia. We consider that the association of chronic trauma, a classic modifying factor, resulting from parafunctional activity and the reduction of salivary flow promoted- among other primary organic reasons, prior to radio and chemotherapy treatment- due to the potential narrowing of the Stenon's duct due to masticatory dysfunction, as a promoter of the loss of local homeostasis and not control of endogenous and / or exogenous initiators, they contributed to the development of the neoplastic condition.

\section{Descriptors: Carcinoma, Squamous Cell; Saliva; Trigger Points; Homeostasis.}

\section{Resumen}

El carcinoma de células escamosas (CCE) es la neoplasia maligna más común de la cavidad oral, y sus principales agentes etiológicos: alcohol, tabaco y virus del papiloma humano (VPH) de alto riesgo, sin embargo, existen otras posibilidades etiopatogénicas que aún no han sido ayudadas por la ciencia. Este artículo informa sobre un caso de una paciente de 48 años, no fumadora, no alcohólica y sin signos de infección por el virus del VPH, que se queja de lesión nodular en el abdomen lingual. Informó el hábito de "chupar la lengua" desde una edad temprana, boca seca y boca ardiente durante algunos meses y, en el examen físico, presentó ordeño negativo de las glándulas parótidas, baja colección en las glándulas sublinguales y submandibulares. Mostró signos de compromiso cervical, masetero y, en consecuencia, de músculos buccinatorios, una condición que puede contribuir físicamente a la estenosis del conducto parotídeo y a la reducción de la secreción parotídea. Después de diagnosticar CCE, el paciente se sometió a tratamiento quirúrgico, de radio y quimioterapia. Para el control del hábito parafuncional, probablemente relacionado con la lesión que evolucionó a CCE, se realizó lo siguiente: uso de dispositivo interoclusal, fisioterapia y crioterapia con prescripción de saliva artificial y crema reparadora para lesiones de la mucosa, como resultado de hipo/asialia. Consideramos que la asociación del trauma crónico, un factor modificador clásico, resultante de la actividad parafuncional y la reducción del flujo salival promovió- entre otras razones orgánicas primarias, antes del tratamiento con radio y quimioterapia- debido al posible estrechamiento del conducto de Stenon debido a la disfunción masticatoria, como promotores de la pérdida de la homeostasis local y no del control de iniciadores endógenos y / o exógenos, contribuyeron al desarrollo de la condición neoplásica.

Descriptores: Carcinoma de Células Escamosas; Saliva; Puntos Disparadores; Homeostasis.

INTRODUÇÃO

\section{O carcinoma espinocelular (CEC)} representa $90 \%$ de todos os cânceres orais. Apesar do progresso em pesquisa e terapias, constitui o top 10 da incidência de câncer e, em relação à sobrevida, não houve melhora significativa nos últimos anos ${ }^{1,2}$. Os fatores de risco que desenvolvem a doença, embora independentes, têm ação aparentemente sinérgica. Entre eles, os mais expressivos são tabagismo, alcoolismo e Papiloma Vírus 
Humano (HPV). Secundariamente, e ainda não bem definidos cientificamente, estão os fungos, dieta, imunossupressão, higiene bucal e trauma crônico ${ }^{3}$.

A cavidade bucal é o local de fronteira entre o meio externo e interno do corpo humano. Por isso, são necessários complexos mecanismos de defesa contra patógenos, simultaneamente à proteção da microbiota da região. A saliva, além de participar da formação do bolo alimentar e lubrificação dos tecidos, atua como mantenedor da homeostasia bucal, sendo a primeira barreira biológica contra agentes infecciosos como vírus, bactérias e fungos ${ }^{4}$.

Ao entrar em contato com a saliva, microorganismos patogênicos enfrentam componentes moleculares e celulares da imunidade inata e adaptativa. Do Sistema Imune Inato (SII), os componentes celulares mais estudados são os polimorfonucleares, em destaque os neutrófilos, que migram constantemente do sulco gengival para a cavidade bucal ${ }^{5}$. Dos componentes moleculares do SIl que exercem inúmeras funções, podem ser citadas a lactoferrina (atividade antimicrobiana), lisozima (atividade antibactericida), peroxidase salivar (atividade antibactericida), mucina (proteção a aderências microbianas), histatina (atividade antifúngica) e quitinase (atividade antifúngica), entre diversos outros oligopeptídeos e polipeptídeos. Do Sistema Imune Adaptativo (SIA) destacam-se as imunoglobulinas $\lg \mathrm{A}$, $\lg \mathrm{M}$ e $\lg \mathrm{G}$, responsáveis pela imunidade mais específica e de memória ${ }^{4,6-8}$.

A xerostomia ou sensação subjetiva de "boca seca" notada pelos pacientes e, quando certificada clinicamente, hipo ou assialia, resulta em desequilíbrio biológico: infecções virais, bacterianas e fúngicas oportunistas como as candidoses, dificuldades na mastigação, deglutição, fala, queimação bucal, aumento da susceptibilidade a cáries e úlceras traumáticas ${ }^{9}$. A redução do fluxo salivar pode ser causada por medicamentos, síndromes, estresse, ansiedade, distúrbios, obstruções ou estenoses nas glândulas salivares, que podem advir de alterações físicas durante o percurso dos ductos das glândulas, por exemplo ${ }^{10}$.

A escassez de conhecimento sobre o desenvolvimento do CEC na ausência de fatores normalmente associados à sua etiologia gera um grande desafio diagnóstico. Assim, almeja-se considerar a falta da secreção salivar como promotora da perda de homeostasia local e não controle de iniciadores endógenos e/ou exógenos, concorrendo para o desenvolvimento de condição neoplásica, agravada pelo trauma parafuncional.

CASO CLÍNICO

Paciente do gênero feminino, 48 anos, melanoderma, não tabagista e não etilista compareceu a clínica odontológica localizada na Cidade de Manaus- Amazonas, com queixa de lesão nodular em ventre da língua (Figura 1).

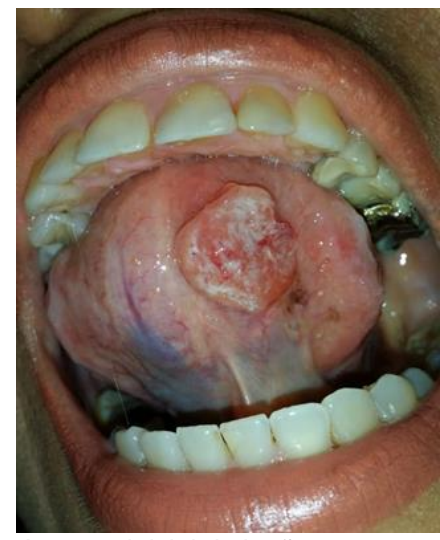

Figura 1: Aspecto inicial da lesão no ventre da língua.

Durante a anamnese, alegou sensação de ardência/queimação bucal generalizada, sensação de "boca seca" e que há aproximadamente um ano notou lesão em língua. Inicialmente foi diagnosticada por outros profissionais como mucocele/afta devido à localização, sinais e sintomas; foram prescritos medicamentos a base de Triancinolona, porém não foi realizado nenhum procedimento cirúrgico para averiguação. Após seis meses do primeiro diagnóstico, a lesão evoluiu em tamanho. Afirmou também, hábito parafuncional de ranger os dentes e de sucção da língua desde tenra idade durante o período notuno e possuir muito estresse. No exame físico extraoral após análise visual nos aspectos frontal (Figura 2) e lateral (Figura 3) foi constatada assimetria postural pelo desnível de altura entre os ombros e anteriorização da cabeça. Ainda notou-se comprometimento dos músculos masseter superficial e profundo, temporal, esternocleidomastóideo e cervicais posteriores bilaterais, principalmente o direito, após palpação de pontos gatilhos locais, seguida de reação de dor e fuga pela paciente. Durante o exame físico intraoral, foi observado lesão exofítica com base pediculada larga, medindo cerca de dois centímetros em seu maior diâmetro localizada em ventre lingual esquerdo. Na superfície da lesão era possível visualizar algumas áreas leucoeritroplásicas, além de edentações. Também foi verificada ordenha negativa de ambas as glândulas parótidas e baixa coleta salivar nas glândulas sublingual e submandibular. Como conduta foi escolhida a realização de biópsia excisional. 


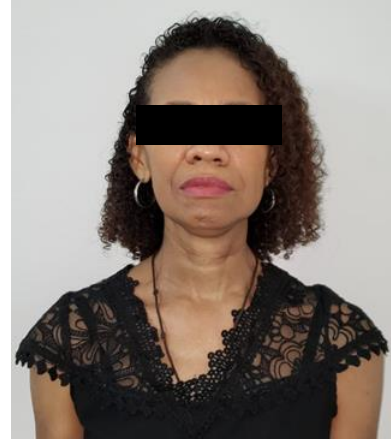

Figura 2: Visão frontal.

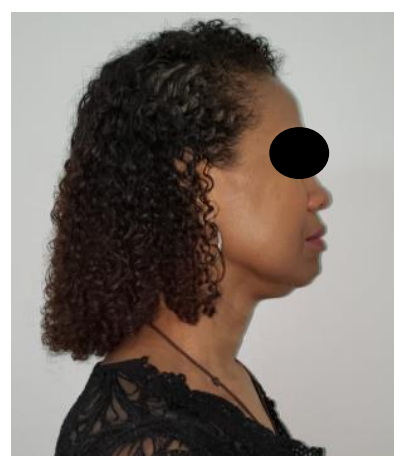

Figura 3: Visão lateral.
Previamente à cirurgia foi averiguado normalidade nos exames laboratoriais. Após análise histopatológica, 0 material foi diagnosticado como Carcinoma Espinocelular pouco diferenciado, apresentando epitélio displásico, com perda de estratificação e adesão intercelular, células hipercromáticas e pleomórficas com mitoses atípicas (Figura 4), além de intenso infiltrado inflamatório. A paciente foi encaminhada para a Fundação Centro de Controle de Oncologia do Estado do Amazonas (FCECON-AM), onde foi realizada glossectomia parcial, esvaziamento cervical bilateral, sessões de radioterapia e quimioterapia.

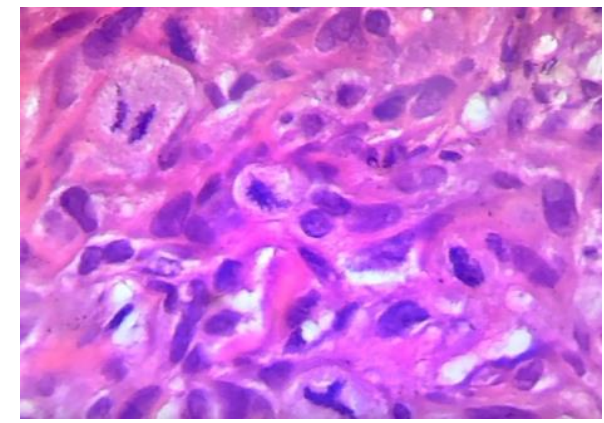

Figura 4: Análise microscópica. Epitélio displásico com núcleos hipercromáticos, pleomórficos e mitoses atípicas.

No segundo mês de tratamento, a paciente retornou ao consultório odontológico apresentando lesões pseudomembranosas características de infecção por Candida albicans (Figura 5), devido ao baixo fluxo salivar e comprometimento imunológico, as lesões regrediram em uma semana após tratamento com Fluconazol sistêmico e Nistatina em suspensão oral. A paciente apresentou efeitos colaterais já esperados devido ao tratamento: enjoos frequentes, mucosite, xerostomia, tosse e escurecimento da pele. Foram realizadas sessões de laser de baixa intensidade Vermelho 1 Joule (J) por ponto em 4 pontos em volta da lesão e $1 \mathrm{~J}$ Infravermelho em seu centro, para promoção da regeneração tecidual, prescritos saliva artificial fluida e em gel para lubrificação bucal e creme a base de Vegelip $\AA+$ triancinolona acetonida + aloe vera + camomila, para auxílio na reparação das lesões mucosas.
Para tratamento da disfunção temporomandibular muscular mastigatória e cervical, agravada pelo esvaziamento cirúrgico de linfonodos locais, a paciente foi instruída na realização de exercícios fisioterápicos três vezes ao dia (Figura 6) e compressa de gelo (crioterapia), preconizadas por Okeson ${ }^{11}$ para recondicionamento muscular e reorganização postural.

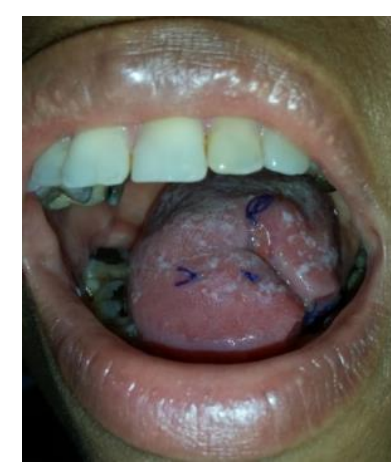

Figura 5: Infecção oportunista por Candida albicans.

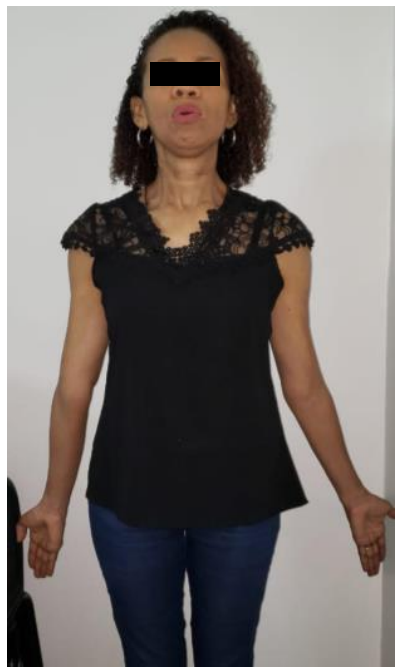

Figura 6: Realização dos exercícios fisioterápicos

Com as mãos espalmadas em forma de concha abaixo da mandíbula, a paciente realiza abertura mínima de 1 centímetro contra a resistência causada pelas mãos, em 3 séries com 10 repetições, por 10 segundos diariamente. Com dedos polegar e indicador entre os dentes superiores e inferiores, a paciente realiza abertura e fechamento bucal confortável e orientada, em 3 séries de 30 vezes diariamente. Com as mãos em palma e um material interposto entre a região lombar e o antebraço, como, por exemplo, um cabo de vassoura, a paciente inspira inclinando a cabeça para trás e espira no retorno da cabeça a posição, em 3 séries de 5 a 10 minutos diariamente. Também foi confeccionado um dispositivo interoclusal em resina acrílica para uso 3 vezes ao dia durante 1 hora após os exercícios e ao dormir.

A paciente foi encaminhada para 0 ortopedista devido à tendinite e bursite presentes no ombro direito. Após um ano de 
tratamento e acompanhamento por diversos profissionais: nutricionistas, psicólogos, fisioterapeutas, fonoaudiólogos, médicos e cirurgiões-dentistas, a paciente permaneceu curada do Carcinoma Espinocelular (Figuras 7 e 8) e houve remissão dos sinais e sintomas da disfunção temporomandibular muscular e melhora na condição de vida.
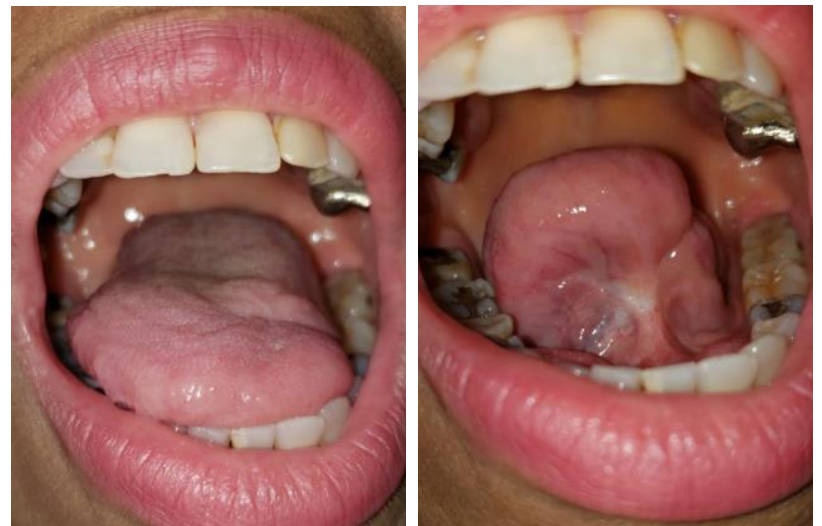

Figuras 7 e 8: Aspecto clínico do dorso e ventre da língua após um ano de tratamento.

\section{DISCUSSÃO}

O CEC em fase inicial pode apresentarse como úlcera que não cura, e pode ser confundida com rompimento de mucoceles ou aftas de repetição. Com a evolução do quadro, pode apresentar-se como lesão exofítica de superfície irregular e cor variante de vermelha ou branca ${ }^{12}$.

As disfunções temporomandibulares (DTM) se estabelecem pela ultrapassagem da tolerância orgânica de músculos e/ou articulações, e tem origem multifatorial, destacando: aspectos psicogênicas (estresse, ansiedade, depressão), traumas locais, desvios posturais, hiperatividades musculares e hábitos parafuncionais. No exame físico é necessário avaliação da postura, da amplitude de movimentação mandibular e dos músculos mastigatórios e cervicais, averiguando sensibilidades e consistências anormais. Durante anamsese é comum dor, sensação de fraqueza, vertigem e zumbidos na orelha ${ }^{13}$.

Há complexas interdependências biomecânicas entre o sistema estomatognático e o restante do corpo humano que podem refletir, por exemplo, no posicionamento dos ombros, levando-os a elevação e protrusão, visto que a hiperatividade dos músculos mastigatórios acarreta na hiperatividade dos músculos cervicais responsáveis pela localização dos ombros e vice-versa ${ }^{14,15}$.

A dor miofascial é um dos sintomas de mais alta incidência na DTM miogênica. Durante hiperatividade formam-se pontos específicos dolorosos, os chamados trigger points ou pontos-gatilhos, resultantes do deficit metabólico local $^{16}$. Para auxílio na dor, movimentação e postura são recomendados o uso de placa interoclusal, exercícios ativos manuais, técnicas de relaxamento e reeducação na vida diária ${ }^{17}$.

O fator psicológico exerce importante função na consolidação das DTMs. Através da maior estimulação do eixo hipocampo-hipófiseadrenal, responsável pelo funcionamento do sistema neuroendócrino, pacientes emocionalmente instáveis, em estados de estresse, depressão ou obsessão, produzem em excesso os hormônios cortisol e adrenalina. A concentração dos hormônios adrenais gera hiperatividade muscular, frequência respiratória rápida, curta, consequentemente respiração anaeróbica nos músculos esqueléticos e formação de pontos-gatilhos ${ }^{18,19}$.

O trauma crônico decorrente de dentes, próteses mal adaptadas, restaurações defeituosas ou hábitos parafuncionais atuam individualmente ou em sinergia provocando irritações mecânicas em mucosa.

Acredita-se que a irritação crônica seria capaz de criar mudanças epigenéticas que, em segundo momento, quando este epitélio mucoso for exposto a outro fator na ausência de equilíbrio local, ocorra a inibição da reparação do DNA e apoptose celular, desempenhando papel na promoção e aceleração do carcinoma oral $^{20}$

A saliva produzida pela glândula parótida é transportada através do ducto parotídeo ou ducto de Stenon, contorna o músculo masséter, adentra 0 músculo bucinador e alcança o vestíbulo da boca. As Disfunções Temporomandibulares musculares, causadas principalmente por hábitos parafuncionais, podem produzir obstruções físicas, como estreitamentos ou obstruções ductais que não permitem acesso da saliva à cavidade oral, provocando hipo/assialia, ardência generalizada, ordinariamente constatada clinicamente com ordenha negativa ou baixa coleta salivar à manobra semiotécnica. Logo, na baixa ou ausência completa da secreção, componente essencial da homeostasia bucal, a cavidade oral torna-se susceptível a microorganismos e seus produtos, fatores ambientais e a quaisquer agentes iniciadores locais.

CONCLUSÃO

Consideramos que a associação do trauma crônico, fator modificador clássico, em ventre lingual resultante da atividade parafuncional presente e a hipo/assialia, 
associada em parte, ao potencial estreitamento do ducto de Stenon em razão da disfunção mastigatória muscular diagnosticada, como promotora da perda de homeostasia local e não controle de iniciadores endógenos e/ou exógenos concorreram para a alteração do DNA celular e desenvolvimento da condição neoplásica.

\section{REFERÊNCIAS}

1. Carli ML, Santos SL, Pereira AAC, Hanemann JAC. Características clínicas, epidemiológicas e microscópicas do câncer bucal diagnosticado na Universidade Federal de Alfenas. Rev Bras Cancerol. 2009;55(3):205-11.

2. Instituto Nacional de Câncer (Brasil). Estatísticas de Câncer. Rio de Janeiro: 2018.

3. Neville WD, Damm DD, Bouquot JE. Patologia Oral e Maxilofacial. 4 ed. Rio de Janeiro: Guanabara Koogan; 2016. Capítulo 10, Patologia Epitelial; p. 374- 89.

4. Mizone-Ono L, Araújo JLP, Dos-Santos MC. Componentes das imunidades inata $e$ adaptativa presentes na saliva humana. Rev Odont UNESP. 2006;35(4):253-61.

5. Takubo T, Yamane T, Tsuda I, Tagawa S, Tatsumi N. Polymorphonuclear neutrophils in saliva and blood: a comparative study of morphology, function and phenotype. $\mathrm{Br} J$ Biomed Sci. 1997;54:260-6.

6. Fábián $T K$, Hermann $P$, Beck $A$, Fejérdy $P$, Fábián G. Salivary defense proteins: their network and role in innate and acquired oral immunity. Int J Mol Sci. 2012;13(4):4295-320.

7. Hernández AA, Aránzazu GC. Características y propiedades físico-químicas de la saliva: una revisón. Ustasalub. 2012;11:101-11.

8. Falcão DP, Mota LMH, Pires Al, Bezerra ACB. Sialometria: aspectos de interesse clínico. Rev Bras Reumatol. 2013;53(6):525-31.

9. Navazesh M, Brightman VJ, Pogoda JM. Relationship of medical status, medications, and salivary flow rates in adults of diferente ages. Oral Surg Oral Med Oral Radiol Endod. 1997;81(2):172-76.

10. Martins BLA, Braga DRLM, Cabral LN. Disfunção massetérica e sialoadenite de refluxo: relato de caso. Arch Health Invest. 2019;8(1):43-7.

11. Okeson JP. Tratamento das desordens temporomandibulares e oclusão. 6. ed. São Paulo: Elsevier; 2008. p. 229-66.

12. Silva CC, Amaral B, Bulhosa JF. Carcinoma Espinocelular da Língua - Fatores de Risco e Importância do Reconhecimento de Lesões Pré-Malignas. Rev Port Estomatol Med Dent Cir Maxilofac. 2010;51:49-55.

13. Bortolleto PPB, Moreira APSM, Madureira PR. Análise dos hábitos parafuncionais $\mathrm{e}$ associação com Disfunção das Articulações
Temporomandibulares. Rev Assoc Paul Cir Dent. 2013;67(3):216-21.

14. Amantea DV, Novaes AP, Campolongo GD, Barros TP. A importância da avaliação postural no paciente com disfunção da articulação temporomandibular. Acta ortop. bras. 2004;12(3):155-59.

15. Halmova K, Holly D, Stanko P. The influence of cranio-cervical rehabilitation in patients with myofascial temporomandibular pain disorders. Bratisl Med J. 2017;118(11):710-13.

16. Freitas DG, Pinheiro ICO, Vantin K, Meinrath NCM, Carvalho NAA. Os efeitos da desativação dos pontos-gatilho miofasciais, da mobilização articular e do exercício de estabilização cervical em uma paciente com disfunção temporomandibular: um estudo de caso. Fisioter mov. 2011;24(1):33-8.

17.Portero PP, Kerzan R, Kusma SZ, Grau-Grullón P. Placas oclusais no tratamento da disfunção temporomandibular (DTM). Gestão \& Saúde. 2009;1(1):36-40.

18. Massena P, Frassetto SS. Aspectos psicológicos associados à disfunção temporomandibular: uma revisão sistemática da literatura. Aletheia. 2015;47/48:169-182.

19. Chrousos GP. Stress and disorders of the stress system. Nat Rev Endocrinol. 2009;5: 374-81.

20.Perez MA, Raimondi AR, Itoiz ME. An experimental model to demonstrate the carcinogenic action of oral chronic traumatic ulcer. J Oral Pathol Med. 2005;34(1):17- 22.

\section{CONFLITO DE INTERESSES}

Os autores declaram não haver conflitos de interesse

\section{AUTOR PARA CORRESPONDÊNCIA}

\section{Yamille de Lima Souza}

Rua Raimundo Nonato de Castro, 685. Cond Gran Vista, B-402

Ponta Negra

69037-042 Manaus - AM, Brasil

Email: ydls.odo16@uea.edu.br 